\title{
Associations between postpartum phenotypes, cow factors, genetic traits, and reproductive performance in seasonal-calving, pasture-based lactating dairy cows
}

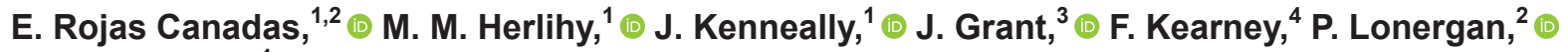 \\ and S. T. Butler ${ }^{1 *}($ () \\ ${ }^{1}$ Animal and Grassland Research and Innovation Centre, Teagasc, Moorepark, Fermoy, Co. Cork, Ireland, P61 C996 \\ ${ }^{2}$ School of Agriculture and Food Science, University College Dublin, Belfield, Dublin, Ireland, D04 N2E \\ ${ }^{3}$ Research Operations Group, Teagasc, Ashtown, Dublin 15, Ireland, D15 DY05 \\ ${ }^{4}$ Irish Cattle Breeding Federation Shinagh, Bandon, Co. Cork, Ireland, P72 X050
}

\section{ABSTRACT}

The objective of this study was to evaluate associations between corpus luteum (CL) status, uterine health, body condition score (BCS), metabolic status, parity, genetic merit for fertility traits, and reproductive performance in pasture-based dairy cows managed for seasonal reproduction. First- and second-lactation $(\mathrm{n}=2,600)$ spring-calving dairy cows from 35 dairy farms located in Ireland were enrolled in the study. Farms were visited every $2 \mathrm{wk}$, and animals that were at wk 3 (range: $14-27 \mathrm{~d}$ in milk) and wk 7 (range: $42-55$ $\mathrm{d}$ in milk) postpartum were examined. Body condition score was measured using a 1-to-5 scale in 0.25 -point increments. Transrectal ultrasound examination was performed at wk 3 and 7 postpartum to determine presence or absence of CL and ultrasound reproductive tract score (scale of G1-G4). Blood samples were collected at each visit, and the concentrations of glucose, $\beta$-hydroxybutyrate (BHB), and fatty acids (FA) were analyzed using enzymatic colorimetry. Animals were grouped into $3 \mathrm{BCS}$ categories [low $(\leq 2.5)$, target (2.75-3.25), and high ( $\geq 3.5)], 2$ CL categories (present or absent), 2 uterine health status categories (normal or abnormal), and 3 metabolic status categories [good (high glucose, low FA and BHB), poor (low glucose, high FA and BHB), and moderate (all other combinations)]. Fisher's exact test was used to test for associations between variables and was supplemented by logistic regression. More cows with a CL at wk 7 were served during the first $21 \mathrm{~d}$ of the breeding period compared with cows without a CL. Cows classified as having a uterine score of G3 or G4 at wk 3 and 7

Received November 15, 2018.

Accepted September 10, 2019.

*Corresponding author: stephen.butler@teagasc.ie had lower odds of pregnancy establishment during the breeding period compared with animals with a uterine score of G1 or G2. Animals with low BCS at wk 7 had lower odds of pregnancy establishment than cows with a target BCS. Cows classified as having good metabolic status at both wk 3 and wk 7 had greater odds of pregnancy establishment during the first $21 \mathrm{~d}$ of the breeding season than those classified as having poor metabolic status. Overall, primiparous cows had greater reproductive performance than second-parity cows. Animals in the quartiles with the best predicted transmitting ability for survival and calving interval had better reproductive performance compared with animals in the other quartiles. Cows that had better genetic merit for fertility traits and good metabolic status, achieved target BCS, and had a favorable ultrasound reproductive tract score and a CL present at wk 7 postpartum had superior reproductive performance. Key words: uterine infection, anestrus, fertility, genetic merit for fertility traits

\section{INTRODUCTION}

Pasture-based dairy systems managed for seasonal calving require a 12-mo calving interval to maximize pasture nutrient utilization (Dillon et al., 2006). Excellent reproductive performance in this production system is necessary to obtain a concentrated calving pattern during late winter and early spring (Morton, 2010), and calving pattern is a key driver of farm profitability (Shalloo et al., 2014).

It has been reported that approximately 11 to $38 \%$ of cows are anovular at the beginning of the breeding season, and this can be a factor that limits herd submission rates (Rhodes et al., 2003). The beneficial effect of early resumption of ovarian cyclicity remains controversial. Some studies reported that early ovulation resulted in greater pregnancies per $\mathrm{AI}(\mathbf{P} / \mathbf{A I})$ and 
shorter calving to conception interval (Galvão et al., 2010; Bittar et al., 2014); others, however, reported delayed uterine involution (Heppelmann et al., 2013) and detrimental effects on reproductive performance (Smith and Wallace, 1998).

Sheldon et al. (2006) proposed a case definition for clinical endometritis as the presence of purulent discharge detectable in the vagina at $21 \mathrm{~d}$ or more after parturition. Absence of purulent vaginal discharge does not exclude endometritis (Šavc et al., 2016), and it might lead to an erroneous diagnosis of endometritis instead of vaginitis. Ultrasound examination may help to identify pathological conditions in the uterus (Quintela et al., 2012). The amount of fluid and uterine lumen shape detected by ultrasound have been reported to be correlated with the existence of bacterial growth in uterine fluid samples (Mateus et al., 2002) and reproductive performance (Mee et al., 2009; Jaureguiberry et al., 2017).

Temporal changes in BCS are a key driver of cow health and fertility (Berry et al., 2008); BCS at calving, nadir BCS, and BCS losses during the postcalving period have been associated with reproductive performance in confinement (López-Gatius et al., 2003) and pasture-based systems (Roche et al., 2007). Ospina et al. (2010b) reported that animals that had postpartum blood concentrations of fatty acids $(\mathbf{F A}) \geq 0.72$ $\mathrm{mEq} / \mathrm{L}$ or $\mathrm{BHB} \geq 0.96 \mathrm{mmol} / \mathrm{L}$ had a decreased risk of pregnancy within $70 \mathrm{~d}$ after the voluntary waiting period. Conversely, greater circulating concentrations of glucose during the prepartum period and the first $3 \mathrm{wk}$ postpartum have been associated with shorter intervals to pregnancy (Cardoso et al., 2013) and greater odds of pregnancy at first service (Garverick et al., 2013).

Genetic merit for fertility traits affects several organs and tissues involved in fertility performance in dairy cows (Butler, 2013). Animals with poor genetic merit for fertility traits have lesser BCS, unfavorable metabolic status, longer postpartum anestrous intervals, increased incidence of endometritis, inflammation, dysfunctional estrous behavior, and lesser plasma progesterone concentrations during the luteal phase (Cummins et al., 2012b; Moore et al., 2014a; Moran et al., 2017). However, no studies have assessed the associations between individual genetic traits and reproductive performance in dairy cows managed under a seasonally calving, pasture-based system. Therefore, the aim of this study was to identify factors associated with postpartum fertility phenotypes in pasture-based, seasonal-calving dairy cows. Specifically, the objective was to develop a large data set of first- and second-parity cow records to evaluate the associations between corpus luteum (CL) presence, uterine health, BCS, metabolic status, parity, individual genetic traits, and reproductive performance in seasonal-calving, pasture-based lactating dairy cows.

\section{MATERIALS AND METHODS}

All experimental procedures involving cows were approved by the Teagasc Animal Ethics Committee and authorized by the Health Products Regulatory Authority, which is the competent authority in Ireland responsible for the implementation of European Union legislation (Directive 2010/63/EU) for the protection of animals used for scientific purposes.

\section{Herds and Experimental Design}

A prospective, observational cross-sectional study was conducted on 35 pasture-based, seasonal-calving dairy herds located in the province of Munster in Ireland. Within each herd, the study population included first- $(\mathrm{n}=1,637)$ and second- $(\mathrm{n}=1,074)$ lactation dairy cows. All enrolled cows calved during the spring season (February to April) in 2015 ( $\mathrm{n}=24$ herds) and 2016 ( $\mathrm{n}=11$ herds). Only cows that were $\geq 30$ DIM on the planned farm mating start date (MSD) were enrolled. Cows were excluded or withdrawn from the study if the herd owners observed clinical diseases, which included mastitis, lameness, metabolic disorders, and displaced abomasum.

Animals were divided into 3 calving categories based on DIM at the farm MSD. Early-calving cows ( $\mathrm{n}=$ $1,331)$ were $\geq 70$ DIM at MSD, mid-calving cows $(\mathrm{n}=$ 778 ) were 42 to 69 DIM at MSD, and late-calving cows $(\mathrm{n}=486)$ were 30 to 41 DIM at MSD.

The study data collection schedule is outlined in Figure 1. Examinations were performed at wk 3 (14-27 DIM) and wk 7 (42-55 DIM) postpartum, between 7 to $14 \mathrm{~d}$ after first service during the breeding period and 5 to $7 \mathrm{wk}$ after the farm mating end date. To collect all the data at the desired time points, researchers visited all enrolled herds every 2 wk during the postpartum period and every week during the breeding period. The postbreeding visit was carried out once between 34 and $50 \mathrm{~d}$ after the farm mating end date to determine pregnancy status and estimate fetal age. At the wk 3 and 7 visits, postpartum ovarian structures and uterine health were evaluated by transrectal ultrasound (8.5-MHz transrectal transducer; Ibex Pro, E.I. Medical Imaging, Loveland, CO). Body condition score was evaluated by a single observer using a 1-to- 5 scale $(1=$ emaciated; $5=$ obese) with 0.25 -point increments (Edmonson et al., 1989). Cows were classified according to their BCS as low (BCS $\leq 2.5)$, target (BCS 2.75-3.25), or high (BCS $\geq 3.5$ ). 


\section{Ultrasound Evaluation of Ovarian Status and Reproductive Tract Score}

The presence or absence of a CL was recorded during the ultrasound evaluation. Cows with either a follicular cyst $(>25 \mathrm{~mm}$ diameter and no CL) or a luteal cyst were noted but removed from the analysis. Ultrasound reproductive tract score (URTS) was determined by examining the uterine horns based on criteria outlined by Mee et al. (2009) as follows: G1 = a typical spoke wheel-shaped lumen was observed; G2 = a spoke wheel-shaped lumen with an enlarged center filled with a small volume ( $>2$ and $\leq 5 \mathrm{~mm}$ diameter) of fluid of mixed echogenicity was observed; G3 = a stellateshaped lumen filled with a moderate volume $(>5$ and $\leq 10 \mathrm{~mm}$ diameter) of fluid of mixed echogenicity was observed; G4 = a circular-shaped lumen filled with a large volume (>10 $\mathrm{mm}$ diameter) of fluid of mixed echogenicity was observed. These URTS were used to create a binary variable describing uterine health status (UHS). The UHS variable was created due to a low number of animals in the G1 $(\mathrm{n}=54)$ and G4 $(\mathrm{n}=22)$ uterine categories at wk 3 and 7 , respectively, which was consistent with expected physiological postpartum uterine involution. At wk 3, cows diagnosed as having a uterine score of G1 or G2 were considered to have normal UHS, and cows diagnosed as having a uterine score of G3 or G4 were considered to have abnormal UHS. At wk 7, cows diagnosed as having a uterine score of G1 were considered to have normal UHS, and cows diagnosed as having a uterine score of G2, G3, or G4 were considered to have abnormal UHS. Most cows exhibited improvement in URTS (and hence UHS) between wk 3 and 7 ; therefore, we did not calculate a UHS change variable for use in the data analysis.

\section{Blood Sampling and Metabolic Status Assays}

Blood samples were collected via coccygeal venipuncture into evacuated lithium heparin tubes (Vacutainer, Becton Dickinson, Meyla, UK) and stored at $4^{\circ} \mathrm{C}$ during transportation. Samples were centrifuged for $15 \mathrm{~min}$ at $1,500 \times \mathrm{g}$, and plasma was harvested and stored at $-20^{\circ} \mathrm{C}$ until further analysis. The plasma concentrations of glucose, BHB, and FA were analyzed using enzymatic colorimetry (ABX Mira, Montpelier, France). The glucose kits were supplied by Horiba ABX (Montpellier, France), the BHB kits were supplied by Randox Laboratories Ltd. (Crumlin, UK), and the FA kits were supplied by Wako Chemicals GmBH (Neuss, Germany). Cows were categorized as having low glucose, high FA, and high BHB when plasma concentrations met the following criteria: glucose $<60.0 \mathrm{mg} / \mathrm{dL}$, FA $>0.60 \mathrm{mEq} / \mathrm{L}$, and BHB $>0.76 \mathrm{mmol} / \mathrm{L}$ (Ospina et al., 2010a; Garverick et al., 2013).

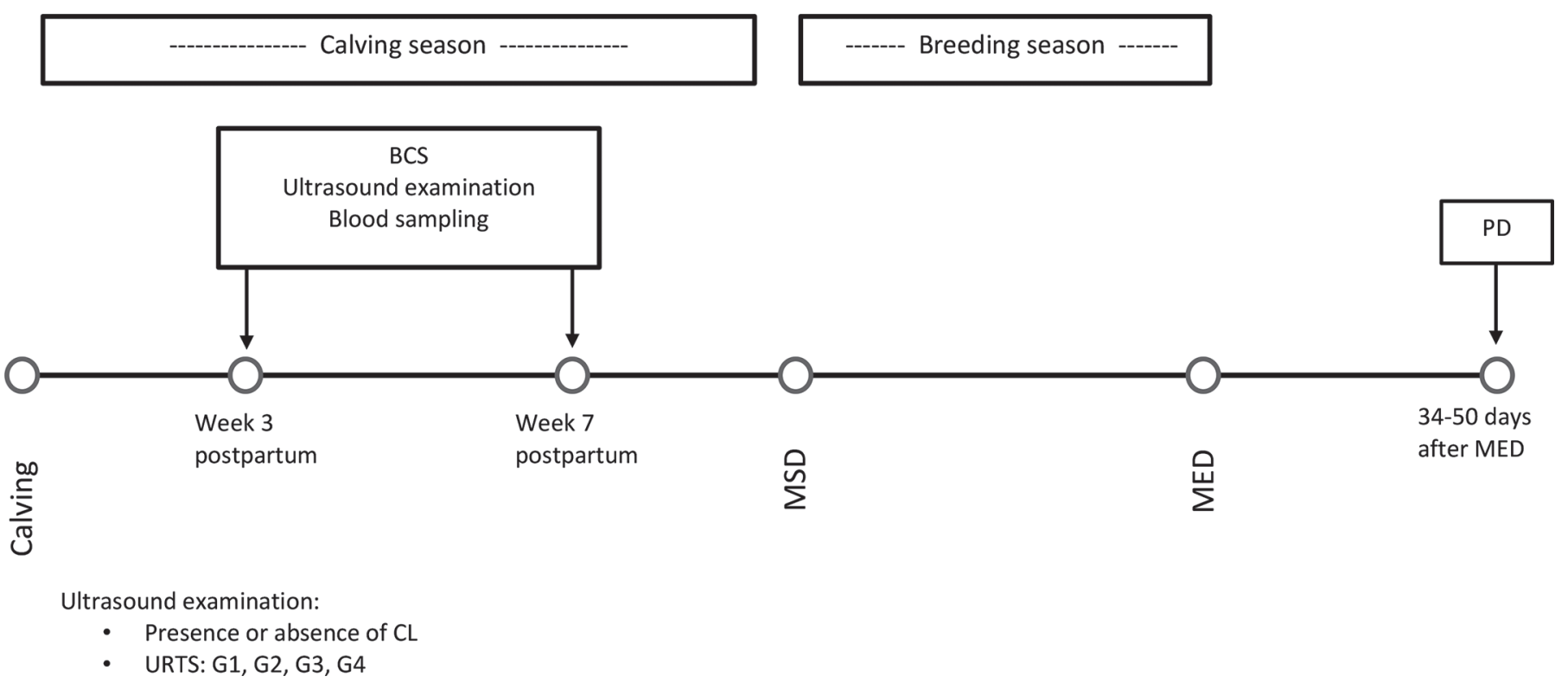

Figure 1. Diagram of activities. During the calving and breeding seasons, farms were visited every 2 wk and every week, respectively. MSD =

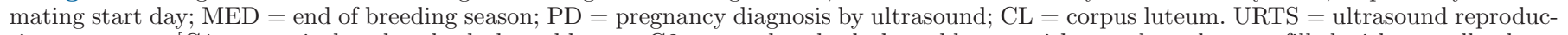
tive tract score [G1 = a typical spoke wheel-shaped lumen; G2 = a spoke wheel-shaped lumen with an enlarged center filled with a small volume

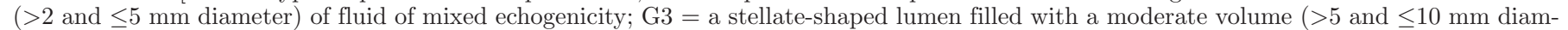
eter) of fluid of mixed echogenicity; G4 = a circular-shaped lumen filled with a large volume (>10 mm diameter) of fluid of mixed echogenicity]. 


\section{Reproductive Parameters}

Reproductive records including farm MSD, service dates, and the mating end date were obtained from the Irish Cattle Breeding Federation profile for each participating herd. The 21-d submission rate (SR21) was constructed by coding cows with an insemination date within the first $21 \mathrm{~d}$ after MSD as 1 and coding those with no insemination date within the first $21 \mathrm{~d}$ as 0. Pregnancy to first insemination $(\mathbf{P} / \mathbf{A I 1})$ was coded as 1 if an animal received only 1 service and was diagnosed as pregnant at the end of the breeding season. Cows with more than 1 service or that were diagnosed as nonpregnant were allocated a P/AI1 of 0 . Pregnancy to second insemination (P/AI2) was coded as 1 if an animal received 2 services and was diagnosed as pregnant at the end of the breeding season. Cows with more than 2 services or that were diagnosed as nonpregnant were allocated a $\mathrm{P} / \mathrm{AI} 2$ of 0 .

Pregnant within $21 \mathrm{~d}$ of the onset of breeding (P21) was coded as 1 if cows had at least 1 service during the first $21 \mathrm{~d}$ of the breeding period and did not receive another service after $21 \mathrm{~d}$ of the breeding period and were subsequently confirmed as pregnant. A cow received a P21 record of 0 if a service was obtained sometime after $21 \mathrm{~d}$ of breeding or if the animal was diagnosed as nonpregnant. Similar descriptions were used for pregnant within $42 \mathrm{~d}(\mathbf{P} 42)$ and $84 \mathrm{~d}(\mathbf{P} 84)$ after MSD. The MSD to conception interval (MSD-CI) was calculated as the interval in days from MSD until the service event that resulted in pregnancy establishment.

\section{Data Handling and Statistical Analysis}

The independent variables investigated were CL status, URTS, UHS, BCS, BCS change, metabolic status, calving date, and parity. For each variable, a cohort of cows was designated as the reference group for determination of odds ratios $(\mathbf{O R} ;=1)$. An OR of $>1$ implies increased likelihood and an OR of $<1$ implies decreased likelihood of a particular outcome relative to the reference group. Cows were assigned to 1 of 4 BCS change categories (change in BCS between wk 3 and 7 postpartum) as follows: lost $\geq 0.5$, lost 0.25 , kept constant, and gained $\geq 0.25$. Blood indicators of metabolic status were assigned to 1 of 3 categories: good (high glucose, low FA and $\mathrm{BHB}$ ), poor (low glucose, high FA and BHB), and moderate (all other possible combinations). On wk 7, due to the low number of animals in the poor category $(\mathrm{n}=66)$, only 2 groups were included in the metabolic status analysis: good and moderate-poor combined. The binary dependent variables investigated were SR21, P/AI1, P/AI2, P21, P42, and P84. To evaluate the marginal associations between independent vari- ables and binary and multinomial dependent variables, Fisher's exact test was used and was supplemented by multiple logistic regression using the LOGISTIC procedure of SAS (version 9.3; SAS Institute Inc., Cary, NC) to calculate $\mathrm{OR}$ and predicted probabilities, including herd, year, parity, and calving date as fixed effects. The postpartum phenotype variables measured at multiple time points (wk 3, wk 7, at AI) and variables where the change between wk 3 and wk 7 was calculated were analyzed individually. The GLIMMIX procedure was used to determine the association between independent variables and MSD-CI, including herd, year, parity, and calving date as fixed effects.

Each subindex of the economic breeding index comprises individual genetic traits (ICBF, 2017). For this study, the fertility subindex and specific individual genetic traits [PTA for calving interval, survival, milk $(\mathrm{kg})$, and milk protein (\%)] were selected for inclusion in the analysis. Calving interval and survival are defined as number of days between successive calving events and longevity in the herd, respectively. Initially, separate logistic regression models were developed for each index as a continuous variable. Then, each genetic trait and the fertility subindex were stratified into quartiles, and logistic regression models were used to calculate $\mathrm{OR}$ and predicted probabilities, including herd, year, parity, and calving date as fixed effects even if they were nonsignificant.

The effects of independent variables on the MSD-CI were evaluated using the Kaplan-Meier survival analysis test (the LIFETEST procedure). Cows that were still not pregnant at the end of the breeding period were right-censored at $84 \mathrm{~d}$ (i.e., all cows were allowed a maximum potential breeding period of $12 \mathrm{wk}$ ).

\section{RESULTS}

The postpartum CL status, URTS, UHS, metabolic status, and BCS phenotypes, and their associations with each other and with parity and genetic traits were described by Rojas Canadas et al. (2020). The current paper describes the relationship between these variables and reproductive performance. The overall mean reproductive performance outcomes across all enrolled herds were SR21 $=93.7 \%(2,573 / 2,745), \mathrm{P} / \mathrm{AI} 1=$ $62.8 \%(1,589 / 2,535), \mathrm{P} / \mathrm{AI} 2=62.2 \%(583 / 937), \mathrm{P} 21=$ $60.4 \%(1,568 / 2,595), \mathrm{P} 42=77.7 \%(2,000 / 2,567)$, and $\mathrm{P} 84=90.5 \%(2,296 / 2,537)$. Herd and year were associated (both $P<0.001$ ) with each reproductive outcome evaluated in the study, highlighting the importance of the herd differences and year-to-year environmental variation on reproductive performance in pasture-based dairy production systems. 


\section{Status}

The incidence of cows that had a CL on the ovary at wk 3 and 7 was $45.5 \%(1,185 / 2,600)$ and $76.9 \%$ $(1,879 / 2,445)$, respectively. There was no association between CL status at wk 3 and any reproductive performance variable (Tables 1 and 2). There was an association between CL status at wk 7 and SR21 $(P=$ $0.02)$ and P21 $(P=0.07)$. Animals that did not have a CL at wk 7 were 0.5 (95\% CI: $0.39-0.78)$ and 0.8 (95\% CI: $0.64-1.03)$ times less likely to be inseminated and to establish a pregnancy during the first $3 \mathrm{wk}$ of the breeding season, respectively, compared with cows that had a CL at wk 7 (Tables 1 and 2).

\section{Uterine Health}

Cows classified as having a uterine score of G3 at wk 7 had reduced likelihood of SR21 $(P=0.03$; Table 3$)$ compared with cows with a uterine score of G1. Cows with a uterine score of G4 at wk 3 had lower P/AI1 ( $P$ $=0.09 ;-7$ percentage points) compared with cows in other URTS categories. Cows with uterine scores of G3 and G4 were less likely to achieve P21, P42, and P84 (Table 4 ), and the mean MSD-CI in cows with a uterine score of G4 was $4.8 \pm 0.19$ and $5.0 \pm 0.24 \mathrm{~d}$ longer $(P=0.07)$ compared with cows with uterine scores of G1 and G2, respectively. Similarly, reproductive performance at the end of the breeding season and MSD-CI were associated with URTS at wk 7 (Table 4; Figure 2). Animals classified as having a uterine score of G4 had lower odds of P84 compared with cows with uterine scores of G1 and G2 $(-12.4$ and -6.4 percentage points, respectively; $P=0.01)$. The MSD-CI was longer $(P=0.04)$ in animals classified as having a uterine score of G4 compared with cows with uterine scores of G1, G2, and G3 $(11.0 \pm 0.2,11.6 \pm 0.18$, and $10.8 \pm$ 0.15 d extra, respectively; Figure 2).

When cows were classified as having normal or abnormal uterine health, an association between UHS at wk 3 and reproductive performance was observed (Tables 3 and 4). Cows with abnormal UHS at wk 3 had reduced odds of P21, P42, and P84 and MSD-CI was $2 \pm 0.01$ $\mathrm{d}$ longer $(P=0.01)$ compared with cows classified as having normal UHS. There were no associations between UHS at wk 7 and reproductive performance in the present study (Tables 3 and 4).

\section{BCS and BCS Change}

Table 5 summarizes the percentages of animals classified as having low, target, and high BCS at wk 3 and 7. Between wk 3 and 7, 4.0\% (104/2,579) of cows were diagnosed as having lost $\geq 0.5$ BCS unit, $32.1 \%$

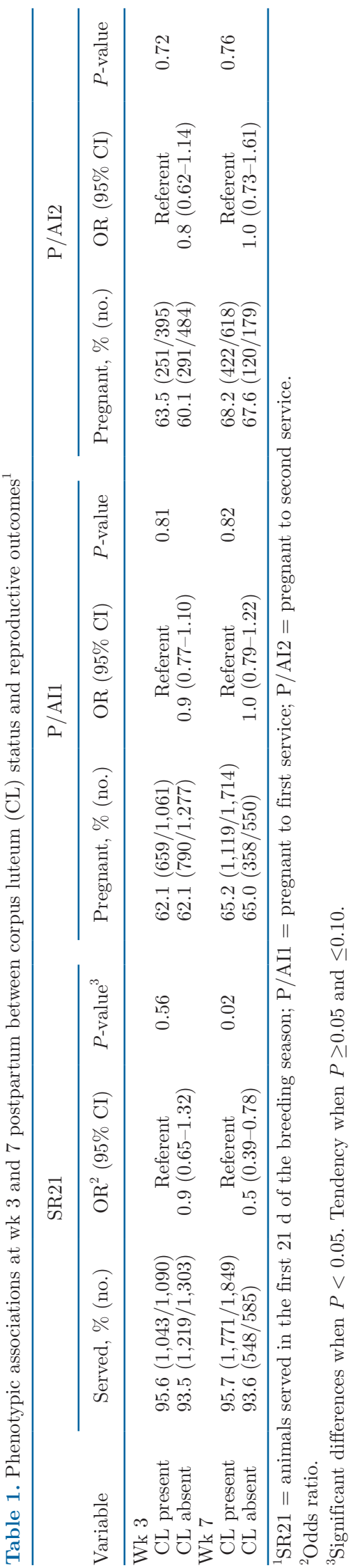




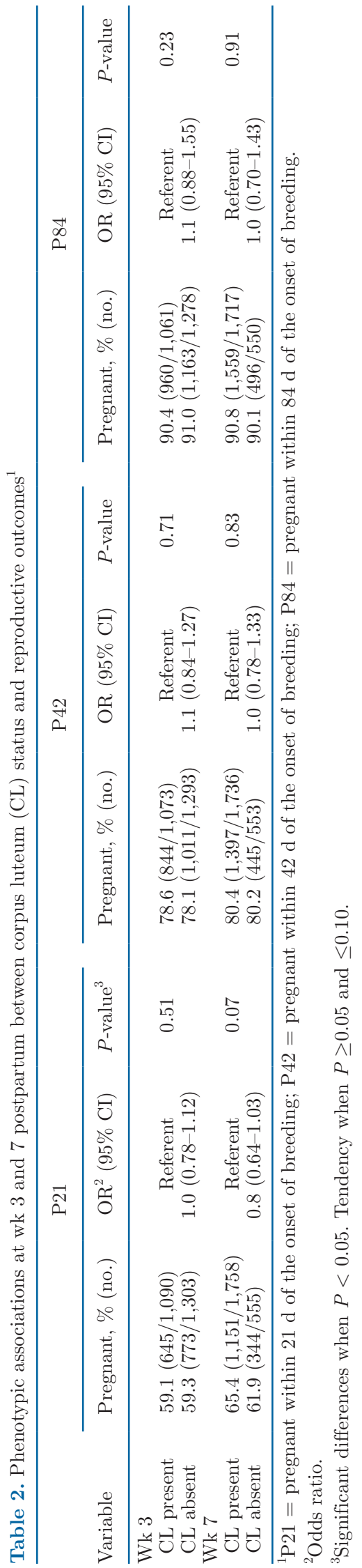

$(829 / 2,579)$ lost 0.25 BCS unit, $51.7 \%(1,333 / 2,579)$ maintained constant BCS, and $12.1 \% \quad(313 / 2,579)$ gained $\geq 0.25$ BCS unit. There was no association between BCS change between wk 3 and 7 postpartum $(P>0.05)$ and any of the reproductive performance variables in the present study. A tendency for lower P84 $(P=0.10)$ and $\mathrm{P} / \mathrm{AI} 2(P=0.06)$ was observed in cows with low BCS at wk 3 (Supplemental Tables S1 and S2, https://doi.org/10.3168/jds.2018-16001). There were associations between BCS at wk 7 and P21, P42, P84 (Supplemental Table S1), and MSD-CI $(P=0.01)$. Cows with low BCS had lesser P21 (-7 percentage points), $\mathrm{P} 42$ ( -9 percentage points), and P84 ( -4 percentage points) compared with cows with target BCS. Moreover, cows with low and high BCS had longer MSD-CI $(3.5 \pm 0.26$ and $2.1 \pm 0.25$ d extra, respectively) compared with cows with target BCS.

\section{Metabolic Status, Parity, and Calving Date}

The proportion of animals classified as having good, moderate, and poor metabolic status was $35.7 \%$ $(818 / 2,294), 59.9 \%(1,376 / 2,294)$, and $4.4 \%(100 / 2,294)$ at wk 3 and $53.5 \%(1,243 / 2,323), 46.1 \%(1,070 / 2,323)$, and $0.4 \%(10 / 2,323)$ at wk 7 , respectively. Lower P/ AI1 was observed in cows classified as having poor metabolic status at wk $3(P=0.10)$ and moderate plus poor metabolic status combined at wk $7(P=0.10)$ compared with cows classified as having good metabolic status. Metabolic status was associated with P21 at both wk $3(P=0.04)$ and wk $7(P=0.03)$ postpartum. Cows classified as having poor metabolic status at wk 3 had lower P21 compared with those classified as having good and moderate metabolic status [(47.6\% (40/84) vs. $60.2 \%(377 / 626)$ and $61.5 \%(654 / 1,062)$, respectively]. Similarly, animals classified as having good metabolic status at wk 7 had greater P21 compared with animals in the moderate plus poor categories combined [63.3\% $(600 / 947)$ vs. $57.0 \%$ (471/825), respectively].

There were associations between parity and calving date with reproductive performance outcomes of interest (Supplemental Tables S3 and S4, https://doi.org/ 10.3168/jds.2018-16001). Primiparous cows had greater $\mathrm{P} / \mathrm{AI} 1$ ( +3 percentage points), $\mathrm{P} / \mathrm{AI} 2(+8$ percentage points), $\mathrm{P} 42(+5$ percentage points $)$, and $\mathrm{P} 84(+2$ percentage points) compared with second-parity cows. Cows in the late-calving category were 0.5 (95\% CI: $0.37-0.90)$ and 0.7 (95\% CI: 0.60-0.88) times less likely to achieve SR21 and P21, respectively, and had a longer MSD-CI $(6.4 \pm 0.2$ and $4.6 \pm 0.2 \mathrm{~d} ; P=0.001)$ compared with cows in the early- and mid-calving groups, respectively. Lower P84 was observed in late-calving cows compared with cows in the early- and mid-calving 


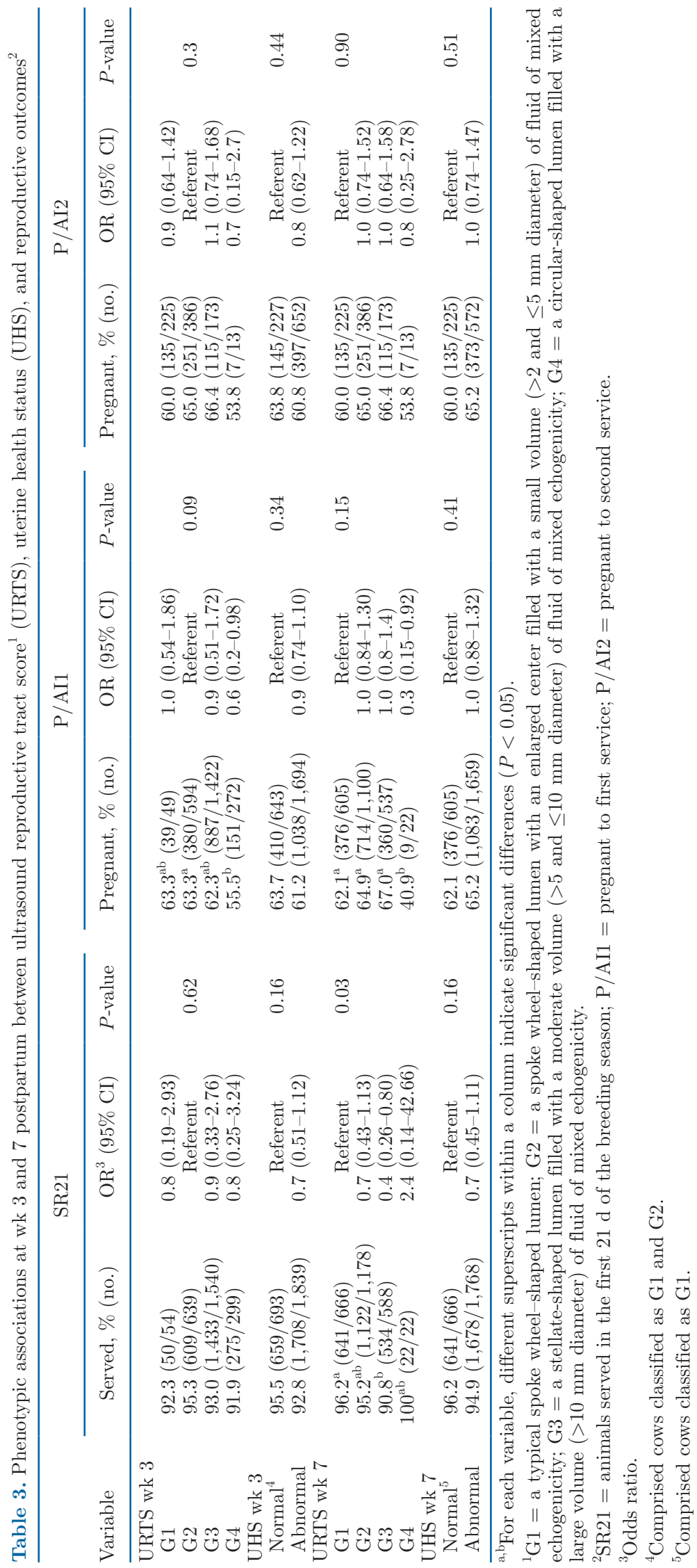




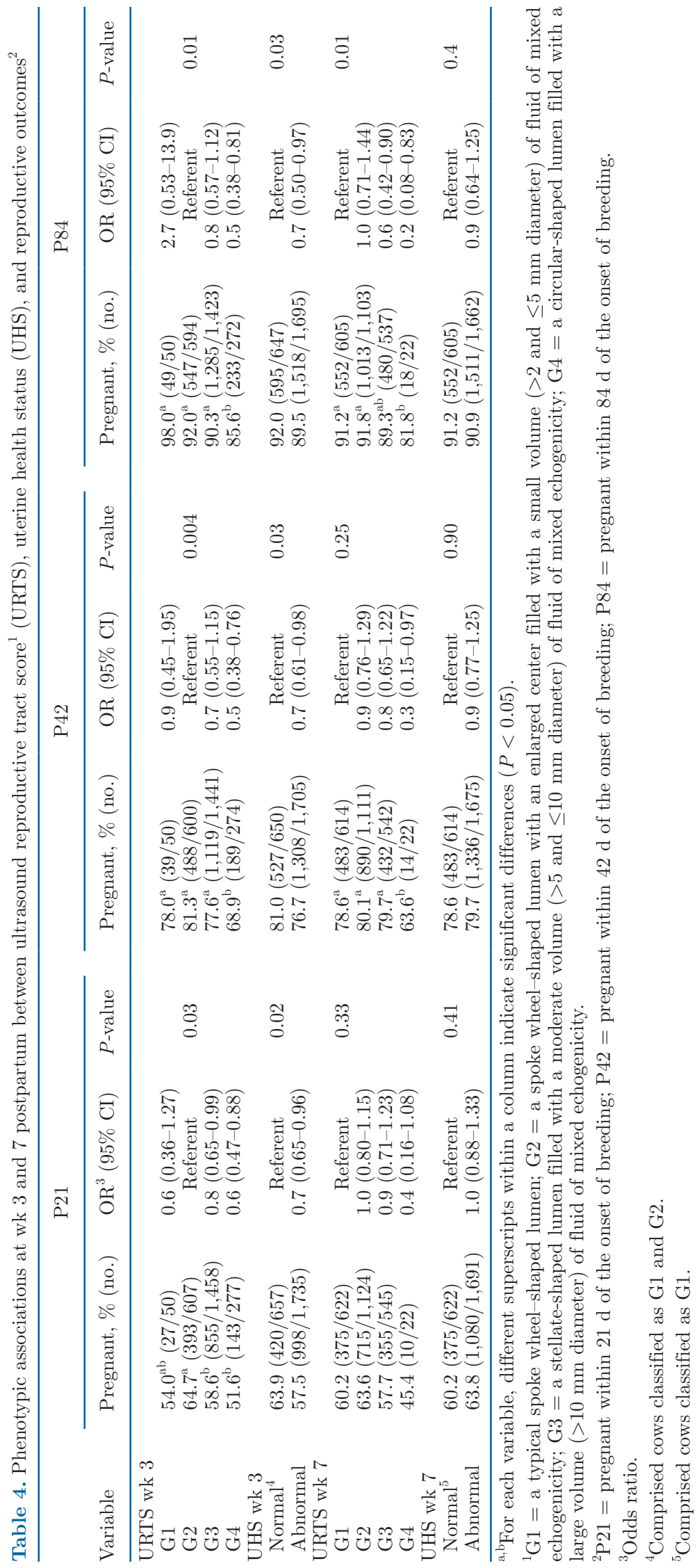



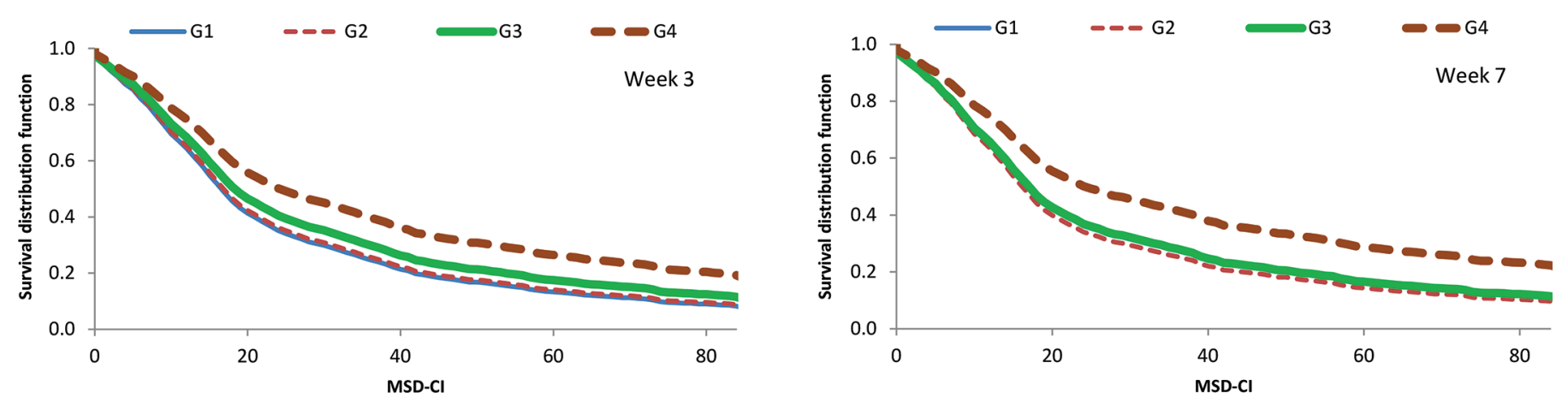

Figure 2. Kaplan-Meier survival curve for associations between mating start date to conception interval (MSD-CI) and uterine reproductive tract score at wk 3 (left; $P=0.07$ ) and wk 7 (right; $P=0.04$ ). G1 = a typical spoke wheel-shaped lumen; G2=a spoke wheel-shaped lumen with an enlarged center filled with a small volume ( $>2$ and $\leq 5 \mathrm{~mm}$ diameter) of fluid of mixed echogenicity; G3 = a stellate-shaped lumen filled with a moderate volume ( $>5$ and $<10 \mathrm{~mm}$ diameter) of fluid of mixed echogenicity; G4 = a circular-shaped lumen filled with a large volume (>10 mm diameter) of fluid of mixed echogenicity. Cows classified as having a uterine score of G4 at both wk 3 and wk 7 had longer MSD-CI compared with cows classified as having uterine scores of G1 and G2.

categories $(-3.1$ and -2.5 percentage points, respectively; $P=0.07)$.

\section{Genetic Traits}

Fertility subindex, PTA for survival, and PTA for calving interval were strongly associated with reproductive performance outcomes of interest (Tables 6 and 7; Supplemental Tables S5 and S6, https://doi.org/10 $.3168 /$ jds.2018-16001). Animals in the quartile with the greatest fertility subindex (i.e., $>77$ ) had greater odds of P/AI1, P/AI2, P21, P42, and P84 and had an MSD-CI that was $4.9 \pm 0.04,2.7 \pm 0.03$, and 2.6 $\pm 0.07 \mathrm{~d}$ shorter $(P<0.0001$; Supplemental Figure S1, https://doi.org/10.3168/jds.2018-16001) compared with animals in the smallest and 2 intermediate quartiles for fertility subindex, respectively. Similarly, cows in the quartile with the smallest PTA for survival (i.e., $\leq 0.9$ ) and cows in the quartile with the longest PTA for calving interval (i.e., $>-1.2 \mathrm{~d}$ ) had reduced odds of P/AI1, P/AI2 (Table 6), P21, P42, and P84 (Table 7) and had the longer MSD-CI (Figure 3) compared with cows in the other 3 quartiles. Cows in the 2 quartiles with the greatest PTA for milk kilograms (i.e., -2.5 to $\leq 109$ and $>109)$ had greater odds of P21 $(P=0.04)$ and P84 $(P=0.007)$ compared with cows in the other
2 quartiles. There was a tendency for reduced SR21 $(P=0.06)$ and P84 $(P=0.10)$ in cows in the quartile with the greatest PTA for milk protein percentage (i.e., $>0.12 \%$; Supplemental Tables S5 and S6, https://doi .org/10.3168/jds.2018-16001).

\section{DISCUSSION}

The present study investigated the associations between different postpartum phenotypes, genetic traits, and reproductive performance in seasonal-calving, pasture-based lactating dairy cows. Overall, the reproductive performance of the herds enrolled in the current study reached the fertility performance targets established for seasonal-calving, pasture-based lactating dairy cows (Butler, 2014): (1) $\geq 90 \%$ of lactating cows submitted for AI in the first $21 \mathrm{~d}$ of the breeding season, (2) 6-wk pregnancy rate of $\geq 70 \%$, and (3) 12 wk pregnancy rate $>90 \%$. Hence, the study animals can be considered to have had good phenotypic fertility overall. It is important to note that this study used only a subpopulation of cows within each herd (first and second calvers, no clinical disease, and calving earlier than $30 \mathrm{~d}$ before the farm MSD) and likely represented the most fertile cows within the herd. Despite this, important associations were identified.

Table 5. Summary of prevalence (\%; no. in parentheses) of cow BCS at wk 3 (14-27 DIM) and wk 7 (42-55 DIM) postpartum

\begin{tabular}{lccc}
\hline BCS $^{1}$ & Wk 3 postpartum & Wk 7 postpartum & AI \\
\hline Target & $89.5(2,327 / 2,599)$ & $84.4(2,066 / 2,445)$ & $94.9(2,409 / 2,538)$ \\
Low & $8.6(226 / 2,599)$ & $14.5(355 / 2,445)$ & $4.6(118 / 2,538)$ \\
High & $1.7(46 / 2,599)$ & $0.9(24 / 2,445)$ & $0.4(11 / 2,538)$ \\
\hline
\end{tabular}

${ }^{1}$ Evaluated by a single observer using a 1 -to- 5 scale $(1=$ emaciated; $5=$ obese $)$ with 0.25 -point increments (Edmonson et al., 1989). Cows were classified according to their BCS as low $(\leq 2.5)$, target $(2.75-3.25)$, or high $(\geq 3.5)$. 

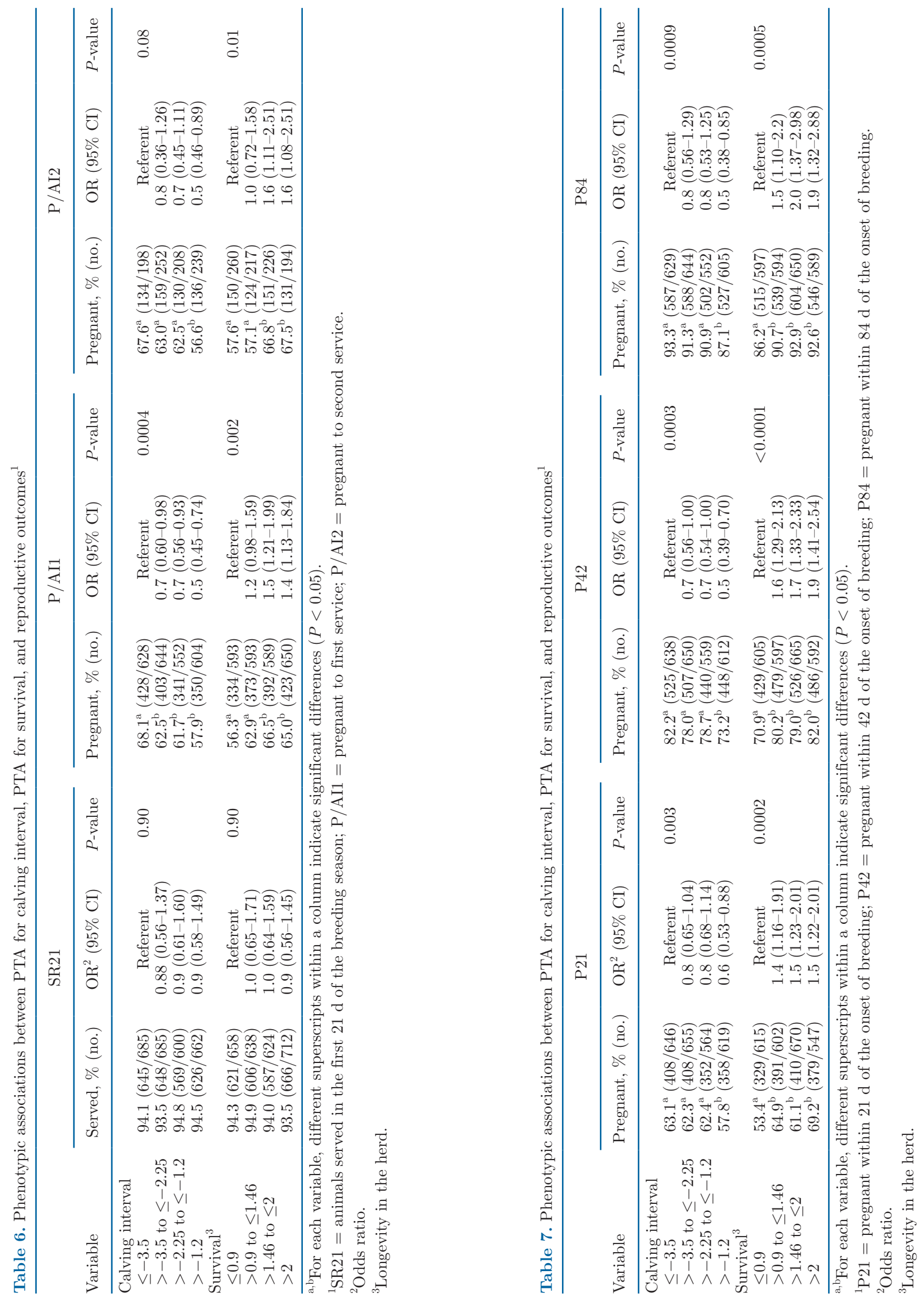

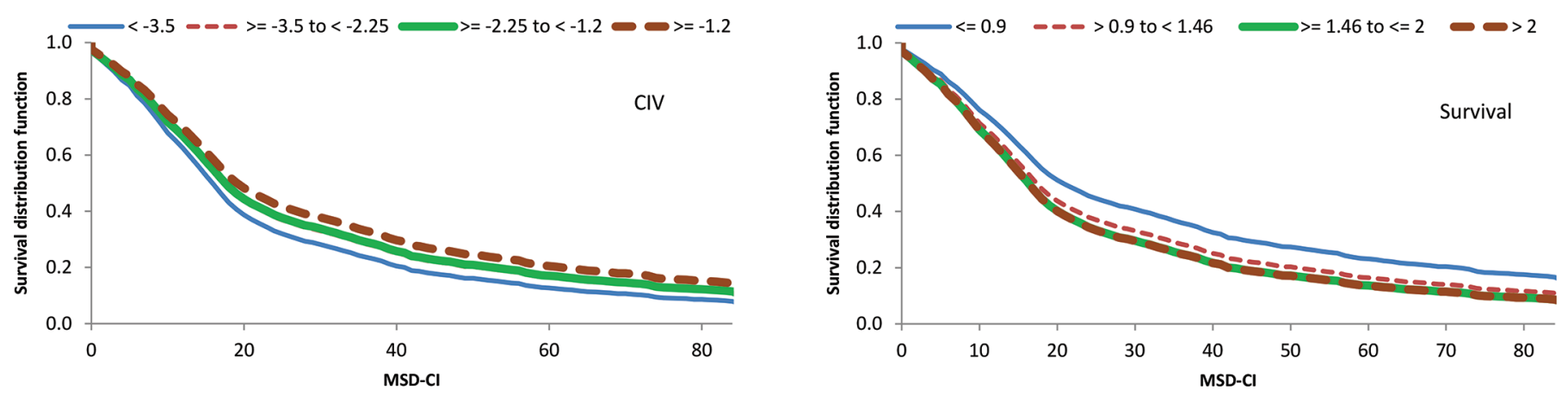

Figure 3. Kaplan-Meier survival curve for associations between mating start date to conception interval (MSD-CI) and PTA for calving interval (CIV; left; $P=0.008$ ) and PTA for survival (longevity in the herd; right; $P=0.008$ ). Cows in the quartiles with the 2 longest PTA for calving interval and in the quartile with the smallest PTA for survival had longer MSD-CI compared with the other 2 quartiles for calving interval and the other 3 quartiles for survival, respectively.

\section{Ovulatory Ovarian Activity}

Ever since Thatcher and Wilcox (1973) stated that the occurrence of multiple estrous cycles during early lactation was associated with increased conception rate, the early resumption of ovulatory ovarian activity has been considered beneficial to fertility. Nevertheless, it is still debated whether early resumption of ovulatory ovarian activity enhances reproductive performance in dairy cows (Smith and Wallace, 1998; Galvão et al., 2010; Bittar et al., 2014). In the present study, cows that had a CL at wk 7 postpartum were more likely to be inseminated during the first $21 \mathrm{~d}$ of the breeding period compared with cows that did not have a CL, but this association was not observed at wk 3 postpartum. Moreover, there was a tendency for greater P21 in cows that had a CL at wk 7 postpartum compared with cows that did not have a CL. Nevertheless, presence of a CL at wk 3 or 7 postpartum was not associated with other reproductive performance outcomes of interest $(\mathrm{P} 42$, $\mathrm{P} 84, \mathrm{P} / \mathrm{AI} 1, \mathrm{P} / \mathrm{AI} 2)$, which is in agreement with the findings of Sakaguchi et al. (2004). Conversely, Santos et al. (2009) and Vieira-Neto et al. (2014) reported greater conception rates at 30 and $58 \mathrm{~d}$ post-AI, greater pregnancy rate at first AI, and shorter calving to pregnancy interval, respectively, in cows that had resumed ovarian cyclicity at 35 and $65 \mathrm{~d}$ postcalving compared with cows that had not resumed ovarian cyclicity at these time points. Timing of examinations differed between studies, which likely explains, at least in part, some of the different findings in these studies.

\section{Uterine Health}

There is general consensus in the literature that endometritis diminishes reproductive performance in cattle (LeBlanc et al., 2002). Endometritis has a del- eterious effect on sperm survival and sperm function (Lonkar and Dedon, 2011), oocyte and embryo development (Hill and Gilbert, 2008; Cerri et al., 2009), and implantation (Kodaman et al., 2004). In the present study, 72.7 and $72.0 \%$ of animals had abnormal UHS at wk 3 (G3 and G4) and wk 7 (G2, G3, and G4), respectively. Ribeiro et al. (2013; 15.5\%) and Mee et al. $(2009 ; 29.0 \%)$ reported a lesser proportion of cows with clinical endometritis and abnormal UHS, respectively, but again the methods and timing of endometritis diagnosis differed between studies.

The results arising from this study highlight the strong association between uterine health and reproductive performance, in agreement with previous reports (LeBlanc, 2008; Gilbert, 2011). We observed a strong association between URTS at both wk 3 and wk 7 and reproductive performance, indicating that ultrasound evaluation of the reproductive tract is a useful tool to predict likelihood of pregnancy failure in dairy cows. It should be noted that there were no differences in reproductive performance between cows diagnosed as having uterine scores of G1 and G2 at both wk 3 and wk 7 . Hence, in the present study, deleterious effects on reproductive performance occurred only in cows diagnosed as having uterine scores of G3 or G4. These findings are in agreement with McDougall et al. (2007) and Mee et al. (2009). When cows were classified as having abnormal UHS at wk 3 (URTS G3 and G4), they had reduced odds of pregnancy establishment during the breeding season (P21, P42, P84) and had a longer MSD-CI compared with cows diagnosed as having normal UHS (URTS G1 and G2), in agreement with McDougall et al. (2007). It is likely that an extended period of subclinical endometritis occurs in cows that were previously diagnosed as having clinical endometritis during the postpartum period despite resolving the clinical problem (Sheldon et al., 2009). 
Prolonged subclinical endometritis is associated with reduced reproductive performance (Madoz et al., 2013). Of note, however, we did not observe a difference in reproductive performance in cows diagnosed with abnormal UHS (URTS G2, G3, and G4) compared with cows with normal UHS (G1) at wk 7. This reflects the relatively lower incidence of G3 and G4 URTS at wk 7 compared with wk 3 and the lack of difference in reproductive performance between cows diagnosed as G1 or G2 at wk 7.

\section{BCS}

Body condition score at calving and at AI and BCS change have previously been described as risk factors affecting reproductive performance in both confinement (see meta-analysis by López-Gatius et al., 2003) and pasture-based systems (Buckley et al., 2003; Roche et al., 2007; Herlihy et al., 2013). In the current study, cows with low BCS at both wk 3 and wk 7 postpartum had poorer reproductive performance compared with cows with target BCS, in agreement with previous reports (Buckley et al., 2003; Santos et al., 2009; Ribeiro et al., 2013). Nevertheless, BCS at AI and BCS change between wk 3 and 7 postpartum were not associated with any reproductive performance variable in the present study, in contrast to previous reports (Roche et al., 2007; Santos et al., 2009). These differences between studies can be explained by differences in the proportion of cows with no change in BCS $[52.2 \%(1,326 / 2,538)$ in the current study vs. $16.4 \%(1,008 / 6,124)$ in Santos et al., 2009] and time of measurement of BCS change (between wk 3 and 7 postpartum in the present study vs. between calving and first AI in Santos et al., 2009).

\section{Metabolic Status, Parity, Calving Date, and Reproductive Performance}

The severity of negative energy balance (NEBAL) influences the concentration of blood metabolites, including FA (Ospina et al., 2013), BHB (McArt et al., 2013), and glucose (Butler, 2003). Postpartum blood concentrations of FA, BHB, and glucose have been used to predict reproductive performance in previous studies (Ospina et al., 2010a; Garverick et al., 2013). In the current study, cows classified as having poor metabolic status at both wk 3 and wk 7 postpartum had reduced odds of pregnancy establishment at the beginning of the breeding period (SR21, P/AI1, and P21) compared with the other 2 categories. These findings are in agreement with Ospina et al. (2010b) and Cardoso et al. (2013). The critical window for follicle exposure to NEBAL may be 6 to $12 \mathrm{wk}$ before ovulation (Garverick et al., 2013). Britt (1994) suggested that adverse events that occur during early follicular development are associated with poor subsequent fertility when cows are inseminated at 50 to $100 \mathrm{~d}$ postpartum. Moreover, Wathes et al. (2011) reported that cows exposed to severe NEBAL experience changes in insulin and IGF1 signaling pathways in the postpartum endometrium, affecting the rate of tissue repair with likely adverse effects on subsequent fertility.

Overall, second-parity cows had poorer reproductive performance than primiparous cows in the present study. This observation might be explained by lower milk yield (Santos et al., 2009) and lower pregnancy loss (Santos et al., 2009) reported in primiparous compared with second-parity cows. Calving date has been reported as an important factor affecting both production (Dillon et al., 1995) and reproductive performance (Garcia and Holmes, 1999) in pasture-based, seasonal-calving systems. In this study, cows in the late-calving category had poorer reproductive performance compared with cows in the early- and mid-calving categories, in agreement with previous reports (Garcia and Holmes, 1999; Herlihy et al., 2013; Sánchez et al., 2018). This reflects the reduced time available to complete postcalving uterine involution, resolve uterine infection, and resume normal estrous cyclicity before the fixed calendar MSD in late-calving cows, as these are all factors that affect reproductive performance (McDougall et al., 2007; Mee et al., 2009; Gautam et al., 2010).

\section{PTA and Fertility Subindex}

Recent studies from our group examining the genetic merit for fertility traits have reported greater DMI and BCS, superior metabolic status and uterine health (Cummins et al., 2012a; Moore et al., 2014a; Moran et al., 2017), earlier resumption of ovarian cyclicity, and greater luteal phase circulating concentrations of progesterone (Cummins et al., 2012b; Moore et al., 2014b) in cows with good genetic merit for fertility traits compared with cows with poor genetic merit for fertility traits. The results arising from this study highlight the strong associations between fertility subindex and PTA for both calving interval and survival with reproductive performance, in agreement with Fenlon et al. (2017) and Hempstalk et al. (2015). This highlights the importance of selecting for fertility traits and long-term gains that can be achieved in herd phenotypic reproductive performance.

Phenotypic milk protein concentration has been positively associated with a range of measures of reproductive performance in both seasonally calving herds (Patton et al., 2007; Morton et al., 2016) and year-round-calving herds (Miettinen and Setälä, 1993). In the current study, a tendency for reduced odds of 
pregnancy establishment was observed at the last stage of the breeding period (P84) for animals in the quartile with the greatest PTA for milk protein percentage. This observation of an unfavorable association between PTA for milk protein percentage and fertility performance is not consistent with previous studies that demonstrated a favorable association between phenotypic milk protein percentage and fertility performance (Buckley et al., 2003; Morton et al., 2017). It is possible that phenotypic milk protein percentage is reflective of both genetic merit for milk protein percentage and environmental influences related to animal nutritional status. On the other hand, there was a positive association between genetic merit for milk (kg) and reproductive performance, in agreement with phenotypic outcomes reported by others (Berry et al., 2003; Buckley et al., 2003; Morton et al., 2016). Cows in the 2 greatest quartiles for milk $(\mathrm{kg})$ had greater P21 and P84 compared with cows in the other 2 quartiles.

A companion paper from this study reported that PTA for calving interval and survival was associated with uterine health and CL status, but a similar relationship was not observed for fertility subindex (Rojas Canadas et al., 2020). The results arising from this study, however, clearly highlight the strong associations between uterine health, CL status, fertility subindex (and its component traits PTA for calving interval and survival), and reproductive performance. Strong effects on pregnancy establishment were observed within the range of fertility subindex values encountered in the current study, highlighting the long-term gains achievable through selecting for fertility traits.

\section{CONCLUSIONS}

The present study clearly demonstrates that postpartum reproductive phenotypes, bioenergetic status, fertility subindex, and PTA for calving interval, survival, milk $(\mathrm{kg})$, and protein in milk (\%) were all associated with reproductive performance. Ultrasound evaluation of the reproductive tract at wk 3 and 7 postpartum identified an unfavorable association between G3 and G4 uterine scores and reproductive performance. Cows in the quartiles with the greatest fertility subindex, PTA for survival, and milk $(\mathrm{kg})$ and in the quartile with the shortest calving interval had superior reproductive performance compared with cows in the other quartiles for each of these variables. Achieving target BCS, good metabolic status, and presence of a CL by wk 7 postpartum, minimizing the incidence of animals having uterine tract scores of G3 and G4, and selecting animals based on fertility subindex (and its component genetic traits) were all associated with improved repro- ductive performance in seasonal-calving, pasture-based dairy cows.

\section{ACKNOWLEDGMENTS}

The authors thank the Irish Department of Agriculture, Food and the Marine (Dublin, Ireland) for funding this project through RSF award 13S528. This study would not have been possible without the support of the 35 commercial dairy farmers. The assistance of numerous undergraduate placement students is also acknowledged.

\section{REFERENCES}

Berry, D. P., F. Buckley, P. Dillon, R. D. Evans, M. Rath, and R. F. Veerkamp. 2003. Genetic relationships among body condition score, body weight, milk yield, and fertility in dairy cows. J. Dairy Sci. 86:2193-2204.

Berry, D. P., J. R. Roche, and M. P. Coffey. 2008. Body condition score and fertility-More than just a feeling. Pages 107-118 in Proc. Fertility in Dairy Cows-Bridging the Gaps. Liverpool Hope University, Liverpool, UK.

Bittar, J. H. J., P. J. Pinedo, C. A. Risco, J. E. P. Santos, W. W. Thatcher, K. E. Hencken, S. Croyle, M. Gobikrushanth, C. C. Barbosa, A. Vieira-Neto, and K. N. Galvao. 2014. Inducing ovulation early postpartum influences uterine health and fertility in dairy cows. J. Dairy Sci. 97:3558-3569.

Britt, J. H. 1994. Follicular development and fertility: Potential impacts of negative energy balance. Pages 103-112 in Proc. National Reproduction Symposium, Pittsburgh, PA. Texas Agricultural Extension Service.

Buckley, F., K. O'Sullivan, J. F. Mee, R. D. Evans, and P. Dillon. 2003. Relationships among milk yield, body condition, cow weight, and reproduction in spring-calved Holstein-Friesians. J. Dairy Sci. $86: 2308-2319$.

Butler, S. T. 2013. Genetic control of reproduction in dairy cows. Reprod. Fertil. Dev. 26:1-11.

Butler, S. T. 2014. Nutritional management to optimize fertility of dairy cows in pasture-based systems. Animal 8(Suppl. 1):15-26.

Butler, W. R. 2003. Energy balance relationships with follicular development, ovulation and fertility in postpartum dairy cows. Livest. Prod. Sci. 83:211-218.

Cardoso, F. C., S. J. LeBlanc, M. R. Murphy, and J. K. Drackley. 2013. Prepartum nutritional strategy affects reproductive performance in dairy cows. J. Dairy Sci. 96:5859-5871.

Cerri, R. L. A., H. M. Rutigliano, F. S. Lima, D. B. Araujo, and J. E. P. Santos. 2009. Effect of source of supplemental selenium on uterine health and embryo quality in high-producing dairy cows. Theriogenology 71:1127-1137.

Cummins, S. B., P. Lonergan, A. Evans, D. P. Berry, R. D. Evans, and S. T. Butler. 2012a. Genetic merit for fertility traits in Holstein cows: I. Production characteristics and reproductive efficiency in a pasture-based system. J. Dairy Sci. 95:1310-1322.

Cummins, S. B., P. Lonergan, A. Evans, and S. T. Butler. 2012b. Genetic merit for fertility traits in Holstein cows: II. Ovarian follicular and corpus luteum dynamics, reproductive hormones, and estrus behavior. J. Dairy Sci. 95:3698-3710.

Dillon, P., D. P. Berry, R. D. Evans, F. Buckley, and B. Horan. 2006. Consequences of genetic selection for increased milk production in European seasonal pasture based systems of milk production. Livest. Sci. 99:141-158.

Dillon, P., S. Crosse, G. K. Stakelum, and F. Flynn. 1995. The effect of calving date and stocking rate on the performance of springcalving dairy cows. Grass Forage Sci. 50:286-299. 
Edmonson, A. J., I. J. Lean, L. D. Weaver, T. Farver, and G. Webster. 1989. A body condition scoring chart for Holstein dairy cows. J. Dairy Sci. 72:68-78.

Fenlon, C., L. O'Grady, M. L. Doherty, J. Dunnion, L. Shalloo, and S. T. Butler. 2017. The creation and evaluation of a model predicting the probability of conception in seasonal-calving, pasture-based dairy cows. J. Dairy Sci. 100:5550-5563.

Galvão, K. N., M. Frajblat, W. R. Butler, S. B. Brittin, C. L. Guard, and R. O. Gilbert. 2010. Effect of early postpartum ovulation on fertility in dairy cows. Reprod. Domest. Anim. 45:e207-e211.

Garcia, S., and C. Holmes. 1999. Effects of time of calving on the productivity of pasture-based dairy systems: A review. N. Z. J. Agric. Res. 42:347-362.

Garverick, H. A., M. N. Harris, R. Vogel-Bluel, J. D. Sampson, J. Bader, W. R. Lamberson, J. Spain, M. C. Lucy, and R. S. Youngquist. 2013. Concentrations of nonesterified fatty acids and glucose in blood of periparturient dairy cows are indicative of pregnancy success at first insemination. J. Dairy Sci. 96:181-188.

Gautam, G., T. Nakao, K. Yamada, and C. Yoshida. 2010. Defining delayed resumption of ovarian activity postpartum and its impact on subsequent reproductive performance in Holstein cows. Theriogenology 73:180-189.

Gilbert, R. O. 2011. The effects of endometritis on the establishment of pregnancy in cattle. Reprod. Fertil. Dev. 24:252-257.

Hempstalk, K., S. McParland, and D. P. Berry. 2015. Machine learning algorithms for the prediction of conception success to a given insemination in lactating dairy cows. J. Dairy Sci. 98:5262-5273.

Heppelmann, M., A. Brömmling, M. Weinert, M. Piechotta, C. Wrenzycki, and H. Bollwein. 2013. Effect of postpartum suppression of ovulation on uterine involution in dairy cows. Theriogenology 80:519-525.

Herlihy, M. M., M. A. Crowe, D. P. Berry, M. G. Diskin, and S. T. Butler. 2013. Factors associated with fertility outcomes in cows treated with protocols to synchronize estrus and ovulation in seasonal-calving, pasture-based dairy production systems. J. Dairy Sci. 96:1485-1498.

Hill, J., and R. Gilbert. 2008. Reduced quality of bovine embryos cultured in media conditioned by exposure to an inflamed endometrium. Aust. Vet. J. 86:312-316.

ICBF. 2017. What is EBI? Irish Cattle Breeding Federation. Accessed Oct. 24, 2019. https://www.icbf.com/wp/?p=5772.

Jaureguiberry, M., M. J. Giuliodori, A. V. Mang, L. V. Madoz, H. Pothmann, M. Drillich, and R. L. de la Sota. 2017. Repeat breeder cows with fluid in the uterine lumen had poorer fertility. J. Dairy Sci. 100:3083-3085.

Kodaman, P. H., A. Arici, and E. Seli. 2004. Evidence-based diagnosis and management of tubal factor infertility. Curr. Opin. Obstet. Gynecol. 16:221-229.

LeBlanc, S. J. 2008. Postpartum uterine disease and dairy herd reproductive performance: A review. Vet. J. 176:102-114.

LeBlanc, S. J., T. F. Duffield, K. E. Leslie, K. G. Bateman, G. P. Keefe, J. S. Walton, and W. H. Johnson. 2002. Defining and diagnosing postpartum clinical endometritis and its impact on reproductive performance in dairy cows. J. Dairy Sci. 85:2223-2236.

Lonkar, P., and P. C. Dedon. 2011. Reactive species and DNA damage in chronic inflammation: Reconciling chemical mechanisms and biological fates. Int. J. Cancer 128:1999-2009.

López-Gatius, F., J. Yániz, and D. Madriles-Helm. 2003. Effects of body condition score and score change on the reproductive performance of dairy cows: A meta-analysis. Theriogenology 59:801-812.

Madoz, L. V., M. J. Giuliodori, M. Jaureguiberry, J. Plöntzke, M. Drillich, and R. L. de la Sota. 2013. The relationship between endometrial cytology during estrous cycle and cutoff points for the diagnosis of subclinical endometritis in grazing dairy cows. J. Dairy Sci. 96:4333-4339.

Mateus, L., L. L. Lopes da Costa, F. Bernardo, and J. Robalo Silva. 2002. Influence of puerperal uterine infection on uterine involution and postpartum ovarian activity in dairy cows. Reprod. Domest. Anim. 37:31-35.

McArt, J. A., D. V. Nydam, G. R. Oetzel, T. R. Overton, and P. A. Ospina. 2013. Elevated non-esterified fatty acids and $\beta$-hydroxybutyrate and their association with transition dairy cow performance. Vet. J. 198:560-570.

McDougall, S., R. Macaulay, and C. Compton. 2007. Association between endometritis diagnosis using a novel intravaginal device and reproductive performance in dairy cattle. Anim. Reprod. Sci. 99:9-23.

Mee, J. F., F. Buckley, D. Ryan, and P. Dillon. 2009. Pre-breeding ovaro-uterine ultrasonography and its relationship with first service pregnancy rate in seasonal-calving dairy herds. Reprod. Domest. Anim. 44:331-337.

Miettinen, P. V., and J. J. Setälä. 1993. Relationships between subclinical ketosis, milk production and fertility in Finnish dairy cattle. Prev. Vet. Med. 17:1-8.

Moore, S. G., T. Fair, P. Lonergan, and S. T. Butler. 2014a. Genetic merit for fertility traits in Holstein cows: IV. Transition period, uterine health, and resumption of cyclicity. J. Dairy Sci. 97:27402752

Moore, S. G., S. Scully, J. A. Browne, T. Fair, and S. T. Butler 2014b. Genetic merit for fertility traits in Holstein cows: V. Factors affecting circulating progesterone concentrations. J. Dairy Sci. 97:5543-5557.

Moran, B., S. T. Butler, S. G. Moore, D. E. MacHugh, and C. J. Creevey. 2017. Differential gene expression in the endometrium reveals cytoskeletal and immunological genes in lactating dairy cows genetically divergent for fertility traits. Reprod. Fertil. Dev. $29: 274-282$.

Morton, J. M. 2010. Interrelationships between herd-level reproductive performance measures based on intervals from initiation of the breeding program in year-round and seasonal calving dairy herds. J. Dairy Sci. 93:901-910.

Morton, J. M., M. J. Auldist, M. L. Douglas, and K. L. Macmillan. 2016. Associations between milk protein concentration at various stages of lactation and reproductive performance in dairy cows. J Dairy Sci. 99:10044-10056.

Morton, J. M., M. J. Auldist, L. Douglas, and K. L. Macmillan. 2017. Milk protein concentration, estimated breeding value for fertility, and reproductive performance in lactating dairy cows. J. Dairy Sci. 100:5850-5862.

Ospina, P. A., J. A. McArt, T. R. Overton, T. Stokol, and D. V. Nydam. 2013. Using nonesterified fatty acids and $\beta$-hydroxybutyrate concentrations during the transition period for herd-level monitoring of increased risk of disease and decreased reproductive and milking performance. Vet. Clin. North Am. Food Anim. Pract. 29:387-412.

Ospina, P. A., D. V. Nydam, T. Stokol, and T. R. Overton. 2010a. Associations of elevated nonesterified fatty acids and $\beta$-hydroxybutyrate concentrations with early lactation reproductive performance and milk production in transition dairy cattle in the northeastern United States. J. Dairy Sci. 93:1596-1603.

Ospina, P. A., D. V. Nydam, T. Stokol, and T. R. Overton. 2010b. Evaluation of nonesterified fatty acids and $\beta$-hydroxybutyrate in transition dairy cattle in the northeastern United States: Critical thresholds for prediction of clinical diseases. J. Dairy Sci. 93:546554.

Patton, J., D. A. Kenny, S. McNamara, J. F. Mee, F. P. O’Mara, M. G. Diskin, and J. J. Murphy. 2007. Relationships among milk production, energy balance, plasma analytes, and reproduction in Holstein-Friesian cows. J. Dairy Sci. 90:649-658.

Quintela, L. A., M. Barrio, A. I. Peña, J. J. Becerra, J. Cainzos, P. G. Herradón, and C. Díaz. 2012. Use of ultrasound in the reproductive management of dairy cattle. Reprod. Domest. Anim. 47(Suppl. 3):34-44.

Rhodes, F. M., S. McDougall, C. R. Burke, G. A. Verkerk, and K. L. Macmillan. 2003. Invited review: Treatment of cows with an extended postpartum anestrous interval. J. Dairy Sci. 86:1876-1894

Ribeiro, E. S., F. S. Lima, L. F. Greco, R. S. Bisinotto, A. P. A. Monteiro, M. Favoreto, H. Ayres, R. S. Marsola, N. Martinez, W. W Thatcher, and J. E. P. Santos. 2013. Prevalence of periparturient diseases and effects on fertility of seasonally calving grazing dairy cows supplemented with concentrates. J. Dairy Sci. 96:5682-5697. 
Roche, J. R., K. A. Macdonald, C. R. Burke, J. F. Lee, and D. P. Berry. 2007. Associations among body condition score, body weight, and reproductive performance in seasonal-calving dairy cattle. J. Dairy Sci. 90:376-391.

Rojas Canadas, E., M. M. Herlihy, J. Keneally, J. Grant, F. Kearney, P. Lonergan, and S. T. Butler. 2020. Associations between ovarian cyclicity, uterine health, indicators of bioenergetic status, and genetic traits during early lactation in seasonal-calving, pasturebased lactating dairy cows. J. Dairy Sci. 103:1002-1015. https:// doi.org/10.1038/jds.2018-16000.

Sakaguchi, M., Y. Sasamoto, T. Suzuki, Y. Takahashi, and Y. Yamada. 2004. Postpartum ovarian follicular dynamics and estrous activity in lactating dairy cows. J. Dairy Sci. 87:2114-2121.

Sánchez, J. M., F. Randi, C. Passaro, D. Mathew, S. T. Butler, and P. Lonergan. 2018. Effect of human chorionic gonadotrophin administration 2 days after insemination on progesterone concentration and pregnancy per artificial insemination in lactating dairy cows. J. Dairy Sci. 101:6556-6567.

Santos, J. E. P., H. M. Rutigliano, and M. Sá Filho. 2009. Risk factors for resumption of postpartum estrous cycles and embryonic survival in lactating dairy cows. Anim. Reprod. Sci. 110:207-221.

Šavc, M., M. Duane, L. E. O'Grady, J. R. Somers, and M. E. Beltman. 2016. Uterine disease and its effect on subsequent reproductive performance of dairy cattle: A comparison of two cow-side diagnostic methods. Theriogenology 86:1983-1988.

Shalloo, L., A. Cromie, and N. McHugh. 2014. Effect of fertility on the economics of pasture-based dairy systems. Animal 8(Suppl. 1):222-231

Sheldon, I. M., J. Cronin, L. Goetze, G. Donofrio, and H.-J. Schuberth. 2009. Defining postpartum uterine disease and the mechanisms of infection and immunity in the female reproductive tract in cattle. Biol. Reprod. 81:1025-1032.
Sheldon, I. M., G. S. Lewis, S. J. LeBlanc, and R. O. Gilbert. 2006. Defining postpartum uterine disease in cattle. Theriogenology 65:1516-1530

Smith, M. C. A., and J. M. Wallace. 1998. Influence of early post partum ovulation on the re-establishment of pregnancy in multiparous and primiparous dairy cattle. Reprod. Fertil. Dev. 10:207-216.

Thatcher, W. W., and C. J. Wilcox. 1973. Postpartum estrus as an indicator of reproductive status in the dairy cow. J. Dairy Sci. $56: 608-610$

Vieira-Neto, A., R. O. Gilbert, W. R. Butler, J. E. P. Santos, E. S. Ribeiro, M. M. Vercouteren, R. G. Bruno, J. H. J. Bittar, and K. N. Galvão. 2014. Individual and combined effects of anovulation and cytological endometritis on the reproductive performance of dairy cows. J. Dairy Sci. 97:5415-5425.

Wathes, D. C., Z. Cheng, M. A. Fenwick, R. Fitzpatrick, and J. Patton. 2011. Influence of energy balance on the somatotrophic axis and matrix metalloproteinase expression in the endometrium of the postpartum dairy cow. Reproduction 141:269-281.

\section{ORCIDS}

E. Rojas Canadas $\odot$ https://orcid.org/0000-0002-4801-233X

M. M. Herlihy @ https://orcid.org/0000-0002-3886-0300

J. Kenneally @ https://orcid.org/0000-0001-9033-1927

J. Grant (ㄴ) https://orcid.org/0000-0003-1400-1859

P. Lonergan (ㄴ https://orcid.org/0000-0001-5598-5044

S. T. Butler (1) https://orcid.org/0000-0003-1542-8344 